\title{
Antibiotic sensitivity pattern of uropathogens from pregnant women with urinary tract infection in Abakaliki, Nigeria
}

This article was published in the following Dove Press journal:

Infection and Drug Resistance

29 November 2013

Number of times this article has been viewed

RC Onoh'

OUJ Umeora'

VE Egwuatu ${ }^{2}$

PO Ezeonu'

TJP Onoh ${ }^{3}$

'Department of Obstetrics and Gynecology, Federal Teaching Hospital Abakaliki, Ebonyi State, Nigeria;

${ }^{2}$ Department of Obstetrics and Gynecology, Enugu State University

Teaching Hospital, Enugu State, Nigeria; ${ }^{3}$ Department of Pathology, Federal Teaching Hospital Abakaliki, Ebonyi State, Nigeria
Correspondence: RC Onoh

Department of Obstetrics and

Gynecology, Federal Teaching Hospital

Abakaliki, Ebonyi State, PMB I02,

48000 I, Nigeria

Tel +2348037007519

Email dronohrc@gmail.com
Background: Urinary tract infection (UTI) is a common bacterial infection during pregnancy and a significant cause of perinatal and maternal morbidity and mortality. The causative bacteria have remained virtually the same although with variations in individual prevalence. There has been an increasing resistance by these bacteria to the commonly available antibiotics.

Objectives: To determine the prevalence of UTI, the common causative bacteria, and their antibiotic sensitivity pattern among pregnant women with UTI.

Methodology: This is a descriptive study that was carried out at the Obstetrics Department of two tertiary institutions in Abakaliki, Ebonyi State, Nigeria (Federal Medical Center and Ebonyi State University Teaching Hospital) over a period of 12 months. Midstream urine specimens from selected pregnant women with clinical features of UTI were collected for microscopy, culture, and sensitivity. The results were analyzed with the 2008 Epi Info $^{\mathrm{TM}}$ software.

Results: A total of 542 pregnant women presented with symptoms of UTI and were recruited for the study over the study period. Of the 542 pregnant women, $252(46.5 \%)$ had significant bacteriuria with positive urine culture and varying antibiotic sensitivity pattern. The prevalence of symptomatic UTI was 3\%. Escherichia coli was the most common bacteria isolated with a percentage of $50.8 \%$. Other isolated micro organisms included Stapylococcus aereus (52 cultures, $20.6 \%$ ), Proteus mirabilis (24 cultures, 9.5\%), S. saprophyticus (18 cultures, 7.1\%), Streptococcus spp. (14 cultures, 5.6\%), Citrobacter spp. (5 cultures, 2.0\%), Klebsiella spp. (4 cultures, 1.6\%), Enterobacter spp. (4 cultures, 1.6\%), and Pseudomonas spp. (3 cultures, 1.2\%). Levofloxacin had the highest overall antibiotic sensitivity of $92.5 \%$. Others with overall antibiotic sensitivity pattern greater than $50 \%$ included cefpodoxime $(87.3 \%)$, ofloxacin $(77.4 \%)$, ciprofloxacin (66.7\%), ceftriaxone (66.7\%), and gentamicin (50.8\%).

Conclusion: E. coli was the most common etiological agent of UTI in pregnancy with Enterococcus (Staphylococcus) gaining prominence. Cephalosporin and quinolones were shown to be very effective against the organisms causing UTI in these pregnant women.

Keywords: antibiotic sensitivity pattern, pregnancy, urinary tract infection, uropathogens

\section{Introduction}

Urinary tract infection (UTI) is one of the common bacterial infections that complicates pregnancy. ${ }^{1,2}$ In pregnancy it may be symptomatic in the form of urethritis, cystitis, or pyelonephritis or it may remain asymptomatic. ${ }^{2}$ Its significance in pregnancy in view of its associated maternal and fetal morbidity and mortality has been widely evaluated. ${ }^{2}$ Varying prevalence of UTI in pregnancy, with a range of $2 \%-10 \%$, has been reported in different parts of the world.,.$^{3,4}$ The highest prevalence rate has 
been reported in the African-American multiparas, while the lowest prevalence rate axis is found in the affluent white women of lower parity. ${ }^{2}$

The prevalence is increased by several factors. Poor socioeconomic status is reported to be a major risk factor with indigent patients having a fivefold increased risk. ${ }^{5}$ The risk is doubled in sickle cell tract. ${ }^{5}$ Other risk factors include increased age, high parity, poor perineal hygiene, history of recurrent UTI, diabetes mellitus, neurogenic bladder retention, anatomic or functional urinary tract abnormality, and increased frequency of sexual activity. ${ }^{6,7}$ Predisposing determinants of high prevalence of UTI in pregnancy include hormone induced ureteral dilatation, urinary stasis, reduced immune function, and presence of vesicoureteric reflux. ${ }^{1,6,7}$

Studies in developing countries have shown that UTI is usually present at the first antenatal visit and only about $1 \%$ or less pregnant women develop bacteriuria after a negative screening early in pregnancy. ${ }^{6}$ UTI in pregnancy contributes significantly to maternal and perinatal morbidity and mortality. ${ }^{5}$ Maternal complication includes overt pyelonephritis in $25 \%-40 \%$ of patients as pregnancy advances among those with asymptomatic bacteriuria, and in $1 \%-2 \%$ in those without asymptomatic bacteriuria. ${ }^{8}$ Other maternal complications include maternal anemia, hypertension, pre-eclampsia, chronic pyelonephritis, and occasionally, renal failure. ${ }^{4,9}$ The fetus is at risk of prematurity, low birth weight, intrauterine growth restriction, and fetal death. ${ }^{9,10}$

Organisms that cause UTI are those from the normal vaginal, perineal, and fecal flora. ${ }^{2,11}$ They include Escherichia coli, Staphylococcus aureus, Staphylococcus faecalis, Proteus mirabilis, Klebsiella species, and Streptococcus species amongst others. There have been reported cases of resistance to antibiotics by these UTI causing organisms. ${ }^{10,11}$ Following frequent use of broad spectrum antibiotics, the prevalence of these resistant bacteria is mainly due to widespread use of antibiotics in people and animal feeds. ${ }^{9,10}$ These resistance properties are easily transferred between bacteria of different genera through plasmids and other means. ${ }^{11}$ These resistance properties to antibiotics are most often observed in hospital settings although they are still seen in community acquired UTI with an increasing presence of gram-positive cocci like Staphylococci and gram negative organisms like Klebsiella becoming more frequent. ${ }^{12,13}$

UTI could present as an acute infection whereby empirical antibiotics are needed while waiting for the culture and sensitivity result, especially in low resource settings to prevent or reduce maternal and fetal morbidities. There has not been any study done on the antibiotic sensitivity pattern in Ebonyi state and literature is sparse on the antibiotic sensitivity pattern among pregnant women with symptomatic UTI in southeast Nigeria. As a result, this study will help formulate the appropriate antibiotic to be used as an empirical treatment regime in our environment. The aim of this study is to therefore determine the prevalence of UTI in pregnancy and the common causative microbes, as well as their antibiotic sensitivity patterns.

\section{Materials and methods}

This was a descriptive cross-sectional study of pregnant women who presented at the antenatal clinic of Federal Medical Center Abakaliki and Ebonyi State University Teaching Hospital, Abakaliki, Ebonyi State, southeast of Nigeria, over the study period of April 1, 2010 to March 31, 2011. The Federal Medical Center and Ebonyi State University Teaching Hospital are the two tertiary health care facilities located within two kilometers of each other in the capital city of Ebonyi state. At present, they are merged and referred to as Federal Teaching Hospital Abakaliki. They receive referrals mostly from all parts of the state and the neighboring states of Benue, Enugu, Cross River, and Abia. Ebonyi state has an estimated population of 4.3 million and occupies a land mass of $5,935 \mathrm{~km}^{2} .{ }^{14}$ Most women book voluntarily for antenatal care in the center; some may default, while the majority continue with the antenatal care follow-up visit until onset of labor or emergence of complication necessitating hospital admission. The average number of antenatal patients seen every week in both hospitals is about 1,000. The Federal Medical Center undertakes about 1,000 deliveries annually while the Ebonyi State University Teaching Hospital undertakes about 1,500 deliveries annually.

The inclusion criteria included pregnant woman presenting with symptoms referable to UTI at the study site and who gave informed written consent to participate in the study. The exclusion criteria included pregnant women on antibiotics within the last 2 weeks, and those with recent history of instrumentation. Also, those who could not give an informed consent were excluded. Pregnant women with symptoms suggestive of UTI (frequency, urgency, nocturia, dysuria, suprapubic or loin pain with or without fever) that fulfilled the above criteria were selected consecutively on presentation at the antenatal or booking clinic. They were informed about the study and the implication of their participation. They were trained and instructed adequately on how to collect a clean catch midstream urine. This involves initial cleaning of the vulva with copious amounts of clean water. The first part of the urine was voided and about 
$10-15 \mathrm{~mL}$ of the midstream urine was collected into the sterile universal bottles containing $0.5 \mathrm{~g}$ boric acid crystal which had been correctly labeled and distributed to them. Trained nurses supervised the process. The urine samples in the sterile universal bottle were transported to the laboratory for processing within 1 hour and where immediate processing was not possible, the samples were promptly refrigerated at $4{ }^{\circ} \mathrm{C}$ to avoid multiplication of bacteria at room temperature. These samples were subjected to routine microscopy, culture, and sensitivity according to standard practice.

Microscopy involved centrifugation of 5-10 $\mathrm{mL}$ of urine sample in a test tube at 1,500 revolutions per minute. The sediments were poured on to a clean slide and observed under a microscope for casts, pus cells, and red blood cells. Culture of the urine was carried out by inoculating a portion of the urine samples which had been well mixed into Cystein-Lactose-Electrocyte Deficient or MacConkey Agar and Blood agar plate (both Lab M Limited, Heywood, UK) using standard wire loop. The specimens were well streaked on the plate to allow for discrete colonies. Inoculated agar plates were incubated at $37^{\circ} \mathrm{C}$ overnight and read after 24 hours to assess growth of significant bacteriuria. Significant bacteriuria is the presence of at least $10^{5}$ single bacteria colonies per $\mathrm{mL}$ of urine and microscopy of 3-5 pus cells per high power field. Suspected pathogens were identified using morphological features of the colonies, and standard biochemical and sugar utilization tests. ${ }^{15}$ Following identification, the isolated microbes were subjected to antibiotic sensitivity testing using the disc diffusion technique using multidisc (Abtek Biologicals Ltd., Liverpool, UK) and interpreted in accordance with the zone size interpretative chart using the Kirby-Bauer method. ${ }^{15}$

For each selected case with proven symptoms of UTI in pregnancy, information on sociodemographic factors were obtained. These included age, parity, religion, gestational age, marital status, and socioeconomic status as determined by Olusanya et al. ${ }^{16}$

Ethical approval for this study was given by the ethics and research committee of the Federal Medical Center as well as Ebonyi State University Teaching Hospital Abakaliki, Ebonyi State.

All information about the clients was entered into a standard proforma designed for this study. The coded data were entered into the computer using $2008 \mathrm{Epi}^{\mathrm{Info}}{ }^{\mathrm{TM}}$ statistical software (version 3.5.1, Centers for Disease Control, Atlanta, GA, USA). Descriptive analysis was used for the sociodemographic characteristic and other variables. Bivariate analysis and multivariate analysis were done by stratification of variables and this was used to identify the level of antibiotic sensitivity pattern of the isolated uropathogens.

\section{Results}

There were 252 laboratory confirmed cases of UTI out of the 542 pregnant women who presented with symptoms of UTI. This amounted to a $46.5 \%$ positive culture rate. The total number of antenatal visits seen during the study period was 8,558 . This gives a prevalence of $3.0 \%$.

The mean age of pregnant women with positive culture of UTI was $27.9 \pm 4.7$ years with a range of 17-43 years. The majority (156 women, $61.9 \%$ ) were within the age range of 20-29 years. The majority were married (246 women, $97.6 \%$ ), belonged to social class I (75 women, $29.8 \%$ ), and were primigravida (96 women, 37.8\%). There were 120 Roman Catholics (47.6\%). The majority of the pregnant women with UTI were at third trimester gestational age (132 women, $52.4 \%$ ). The mean parity was $1.5 \pm 1.7$ with a range of $0-8$. The mean gestational age was $26.1 \pm 9.3$ weeks with a range of 4-41 weeks (Table 1).

Table I Sociodemographic characteristics of pregnant women with urinary tract infection

\begin{tabular}{|c|c|c|}
\hline Variables & Numbers $(n=252)$ & Percentages (\%) \\
\hline \multicolumn{3}{|l|}{ Age (years) } \\
\hline$<20$ & 9 & 3.6 \\
\hline $20-29$ & 156 & 61.9 \\
\hline $30-39$ & 83 & 32.9 \\
\hline$\geq 40$ & 4 & 1.6 \\
\hline \multicolumn{3}{|l|}{ Marital status } \\
\hline Single & 6 & 2.4 \\
\hline Married & 246 & 97.6 \\
\hline \multicolumn{3}{|l|}{ Social class } \\
\hline I & 75 & 29.8 \\
\hline ॥ & 55 & 21.8 \\
\hline III & 54 & 21.4 \\
\hline IV & 51 & 20.2 \\
\hline$\vee$ & 17 & 6.7 \\
\hline \multicolumn{3}{|l|}{ Religion } \\
\hline Protestants & 51 & 20.2 \\
\hline Pentecostals & 79 & 31.3 \\
\hline Roman Catholics & 120 & 47.6 \\
\hline Muslims & 2 & 0.8 \\
\hline \multicolumn{3}{|l|}{ Parity } \\
\hline Primigravida & 96 & 38.1 \\
\hline Primipara & 81 & 32.2 \\
\hline Multipara & 21 & 8.3 \\
\hline Grandmultipara & 54 & 21.4 \\
\hline \multicolumn{3}{|l|}{ Gestational age } \\
\hline First trimester & 34 & 13.5 \\
\hline Second trimester & 86 & 34.1 \\
\hline Third trimester & 132 & 52.4 \\
\hline
\end{tabular}

Note: Social class levels are determined by adding together male (I for professionals, 2 for skilled worker or middle level, 3 for unskilled worker) and female ( 0 for tertiary school, I for secondary school, 2 for no formal education or primary school) scores. 
Table 2 Organisms isolated from pregnant women with urinary tract infection

\begin{tabular}{lll}
\hline Organisms & $\begin{array}{l}\text { Numbers } \\
(\mathbf{n}=\mathbf{2 5 2})\end{array}$ & $\begin{array}{l}\text { Percentages } \\
\mathbf{( \% )}\end{array}$ \\
\hline Escherichia coli & 128 & 50.8 \\
Staphylococcus aureus & 52 & 20.6 \\
Proteus mirabilis & 24 & 9.5 \\
Staphylococcus saprophyticus & 18 & 7.1 \\
Streptcoccus spp. & 14 & 5.6 \\
Citrobacter spp. & 5 & 2.0 \\
Klebsiella spp. & 4 & 1.6 \\
Enterobacter spp. & 4 & 1.6 \\
Pseudomonas spp. & 3 & 1.2 \\
\hline
\end{tabular}

The uropathogens isolated are presented in Table 2 and are illustrated in Figure 1. There were 252 bacterial isolates. E. coli was the most common organism isolated accounting for 128 (50.8\%) of the total isolates. This was followed by $S$. aureus which accounted for $52(20.6 \%)$ of the isolates. The frequency of occurrence of the remaining bacteria isolates included: P. mirabilis, 24 (9.5\%); S. saprophyticus, 18 (7.1\%); Streptococcus spp., 14 (5.6\%); Citrobacter spp., 5 (2.0\%); Klebsiella spp., 4 (1.6\%); Enterobacter spp., 4 (1.6\%); and Pseudomonas spp., $3(1.2 \%)$.

Table 3 shows the overall antibiotic sensitivity pattern of bacterial isolates. Levofloxacin had the highest overall sensitivity of $92.5 \%$. This was closely followed by cefpodoxime with $87.3 \%$. Ofloxacin, ciprofloxacin, and ceftriaxone had overall sensitivities above $60 \%$ but below $80 \%$. Gentamicin had an overall sensitivity of $50.8 \%$. Other antibiotics have their overall antibiotic sensitivity pattern below $50 \%$ and are distributed as follows: streptomycin $38.1 \%$, nitrofurantoin $33.7 \%$, nalidixic acid $21.4 \%$, chloramphenicol $19.8 \%$, tetracycline $15.9 \%$, ampiclox $10 \%$, cloxacillin $4.4 \%$, amoxicillin $1.2 \%$, and cotrimoxazole $0.4 \%$. Figure 2 illustrates antibiotics with overall sensitivity pattern $\geq 50 \%$. These drugs include gentamicin, ofloxacin, ciprofloxacin, ceftriaxone, cefpodoxime, and levofloxacin.

Table 4 shows the antibiotic sensitivity pattern of the bacterial isolates from pregnant women with UTI. E. coli showed $93.0 \%$ sensitivity to levofloxacin, $88.3 \%$ to cefpodoxime, $76.6 \%$ to ofloxacin, $68 \%$ to ciprofloxacin, $62.5 \%$ to ceftriaxone, and less than $50 \%$ sensitivity pattern to other antibiotics. S. aureus showed $90.4 \%$ sensitivity to cefpodoxime, $88.5 \%$ sensitivity to levofloxacin, $82.7 \%$ to ofloxacin, $75 \%$ to ciprofloxacin, $67.3 \%$ to ceftriaxone, $57.7 \%$ to gentamicin and nitrofurantoin while sensitivity to cotrimoxazole and amoxicillin was $0 \%$, and sensitivity to streptomycin, nalidixic acid, chloramphenicol, tetracycline, and cloxacillin was less than $50 \%$.

Gross $100 \%$ sensitivity was noted in the sensitivity pattern of Citrobacter to ofloxacin, Klebsiella to levofloxacin, ceftriaxone, cefpodoxime, and streptomycin, Pseudomonas to levofloxacin and cefpodoxime, and Enterobacter and Streptococcus spp. to levofloxacin. The antibiotic sensitivity pattern

\section{Percentages}
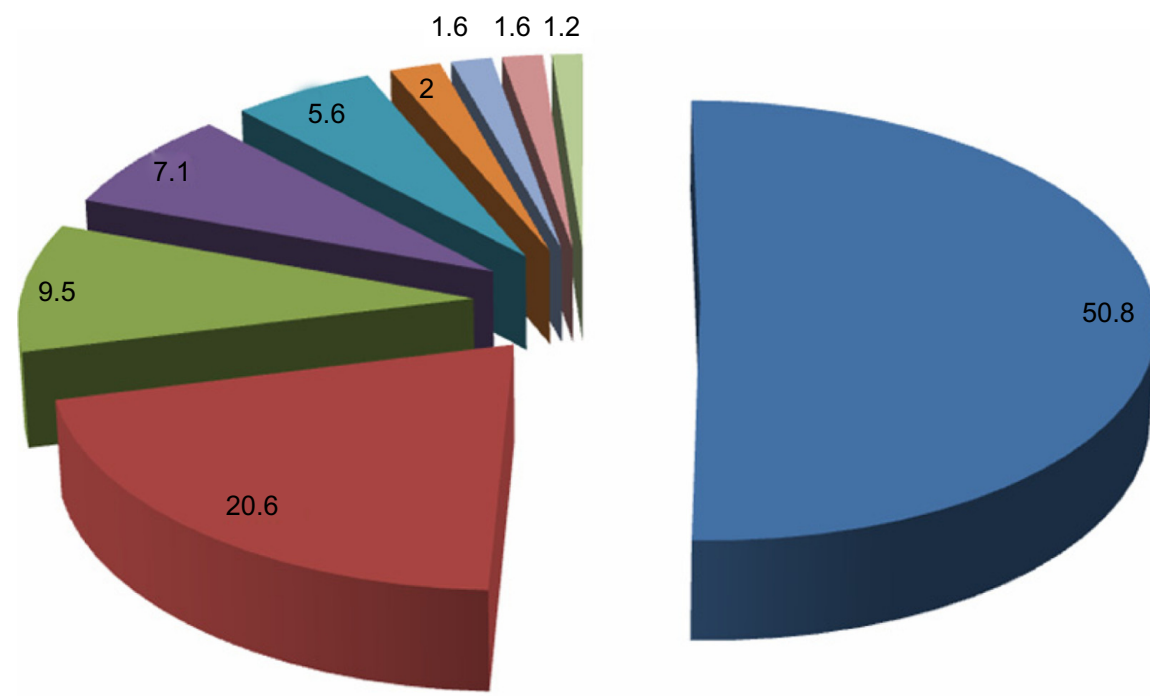

E. coli

- S. aureus

P. mirabilis

-S. saprophyticus

- Strep spp.

Citrobacter

Klebsiella

Enterobacter

- Pseudomonas

Figure I Pie chart showing uropathogens isolated from pregnant women with urinary tract infection. 
Table 3 Overall antibiotic sensitivity pattern (irrespective of bacterial isolates) to the isolated organisms

\begin{tabular}{llll}
\hline Antibiotic & Frequency & \multicolumn{2}{c}{ Percentages (\%) } \\
\cline { 3 - 4 } & & $\mathbf{S}^{\mathbf{a}}$ & $\mathbf{R}^{\mathbf{b}}$ \\
\hline Levofloxacin & 233 & 92.5 & 7.5 \\
Cefpodoxime & 220 & 87.3 & 12.7 \\
Ofloxacin & 195 & 77.4 & 22.6 \\
Ciprofloxacin & 163 & 64.7 & 35.3 \\
Ceftriaxone & 163 & 64.7 & 35.3 \\
Gentamycin & 128 & 50.8 & 49.2 \\
Streptomycin & 96 & 38.1 & 61.9 \\
Nitrofurantoin & 85 & 33.7 & 66.3 \\
Nalidixic acid & 54 & 21.4 & 78.6 \\
Chloramphenicol & 50 & 19.8 & 80.2 \\
Tetracycline & 40 & 15.9 & 84.1 \\
Amp/clox & 25 & 10.0 & 90.0 \\
Cloxacillin & 11 & 4.4 & 95.6 \\
Amoxicillin & 3 & 1.2 & 98.8 \\
Cotrimoxazole & 1 & 0.4 & 99.6 \\
\hline Notes:S're & & &
\end{tabular}

Notes: a'S' refers to the percentage of organisms that are sensitive; ' $R$ ' refers to the percentage of organisms that are resistant to the drug.

Abbreviation: Amp/clox, ampicillin cloxacillin combination.

of uropathogens to drugs that showed individual sensitivity pattern of $\geq 50 \%$ is further illustrated in Figure 3. These drugs include nalidixic acid, nitrofurantoin, streptomycin, gentamicin, ofloxacin, ciprofloxacin, ceftriaxone, cefpodoxime, and levofloxacin.

\section{Discussion}

The $46.5 \%$ positive culture rate seen in this study was higher than rates reported in pregnant women with symptomatic
UTI of $35.5 \%$ in Ilorin, western Nigeria, ${ }^{10} 31.6 \%$ in Kano, northern Nigeria, ${ }^{17}$ and $32.7 \%$ in Benin, southern Nigeria. ${ }^{18}$ It is lower than the rate reported at Lafia, Nigeria. ${ }^{19}$ In the study done in Ilorin (western part of Nigeria) both pregnant and nonpregnant women with symptomatic UTI were subjects for the case controlled study and the nonpregnant women had a lower positive culture. ${ }^{10}$ This may have contributed to the overall low positive culture rate seen in Ilorin. ${ }^{10}$ The high positive culture rate in this study could be because most of our clients were literate and understood the inclusion and exclusion criteria. Also, the research assistants, laboratory personnel, and the pregnant women were well trained and they observed all the aseptic procedures from specimen collection to specimen analysis. Contrary to the findings in our study, the predominant social classes in the study done in Benin (southern part of Nigeria) were social classes III and IV. ${ }^{18}$

The prevalence of UTI in this study was $3.0 \%$ of the study population. This is lower than $6.2 \%$ seen in Ile-Ife reported by Ezechi et $\mathrm{al}^{9}$ and the $4.5 \%$ seen in Nsukka reported by Aka and Onah. ${ }^{20}$ The low prevalence in this study may be related to the kind of patients that visit our facility for antenatal care. These are mainly elites and urban dwellers. This may differ from the prevalence in the rural area in this state. Also our study was on pregnant women with symptoms of UTI hence asymptomatic patients would have been missed. All trimesters were also included in this

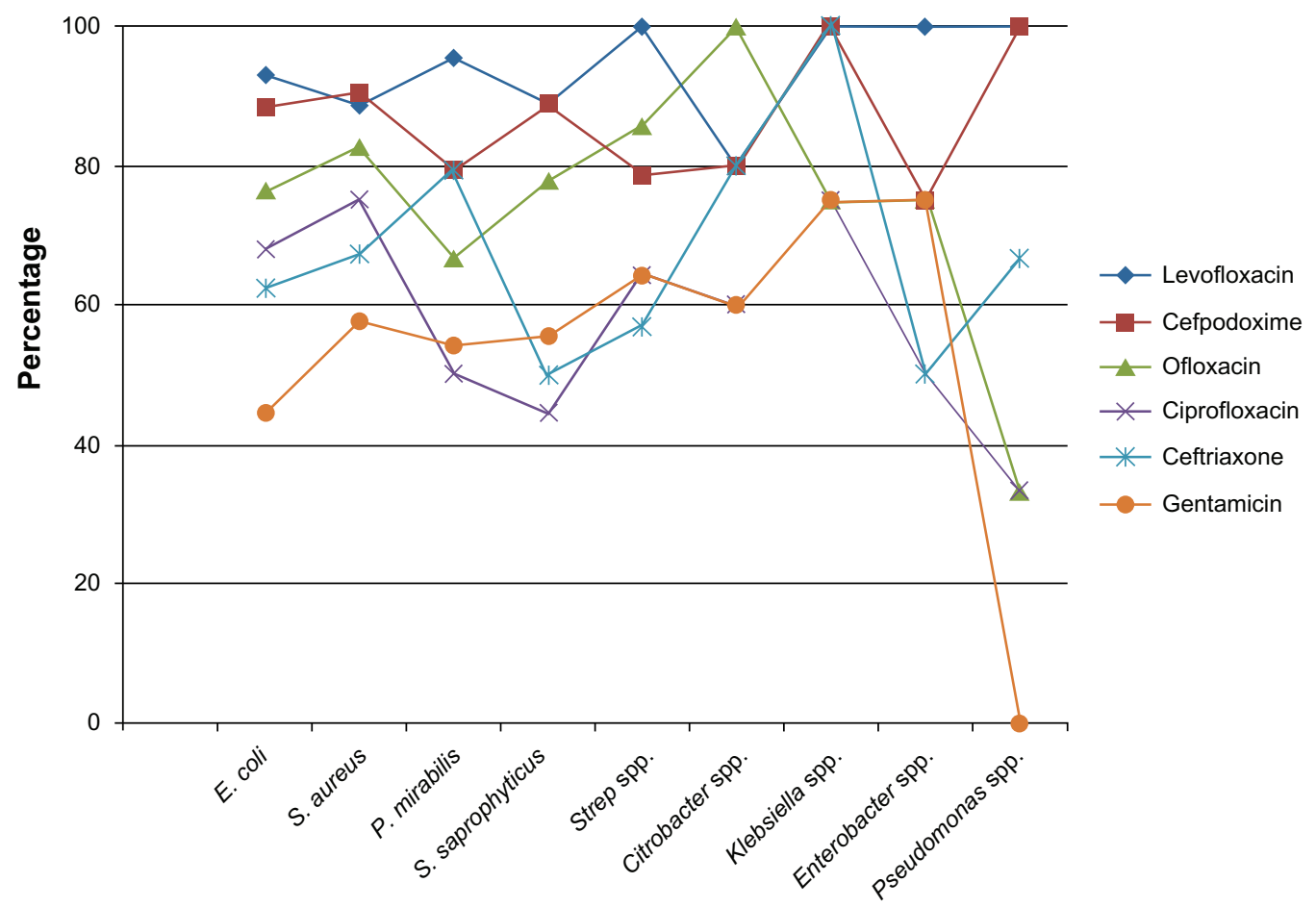

Figure $\mathbf{2}$ Line graph showing antibiotic sensitivity pattern of uropathogens with drugs that showed overall sensitivity pattern of $\geq 50 \%$. 


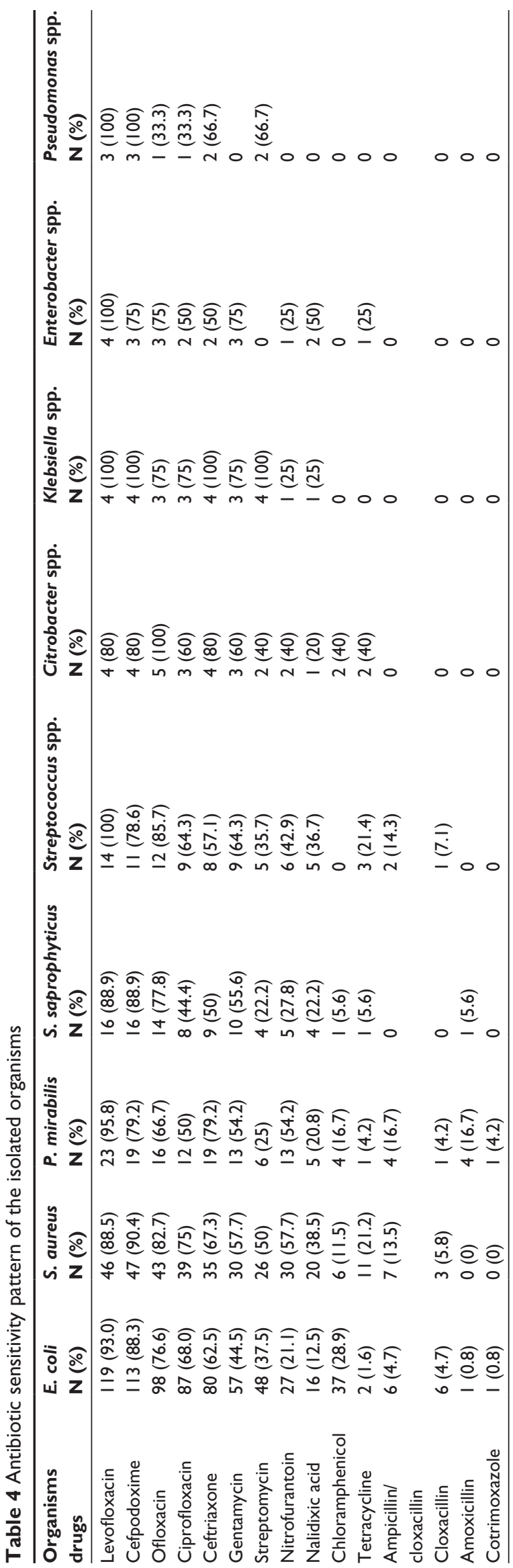

study and the pregnancy hormonal effect on the urinary system may not be well established or pronounced in the early trimester.

E. coli was the most common bacteria isolated in this study and this is similar to most other studies..$^{9,10,13,17-19}$ This supports the fact that most organisms causing UTI are from the lower gastrointestinal tract which acts as a reservoir for organisms like E. coli. ${ }^{6,21}$ The percentage of E. coli in this study was $50.8 \%$ which is less than previous findings in studies done in developed countries. ${ }^{21}$ However, it is higher than recent findings in developing countries like Lafia (30.56\%), northern Nigeria, ${ }^{10}$ Benin (38\%), southern Nigeria, ${ }^{18}$ Ile-Ife (42.2\%), southwest Nigeria, ${ }^{9}$ Ilorin (47.5\%), southwest Nigeria, ${ }^{10}$ Addis Ababa (44\%), ${ }^{22}$ Pakistan (38.\%), ${ }^{23}$ and slightly higher than $50 \%$ in southern India. ${ }^{4}$

S. aureus was the next most common bacteria isolated in this study accounting for $20.6 \%$ of cultures. This is similar to findings in Enugu, ${ }^{24}$ Benin, ${ }^{17}$ and Ilorin,,${ }^{9}$ although it is at variance with other studies. ${ }^{10,19}$ Enterococci has been noted as a significant bacterial isolate from women with UTI in pregnancy. ${ }^{4,10,18,19,24}$ This is in support of the postulation that there tends to be a shift in the percentages of micro organisms causing UTI in favor of Staphylococcus, Klebsiella, and P. mirabilis. ${ }^{718}$ This shift may be due to increased resistance to antibiotics with emergence of resistant strains.

The antibiotic with the overall highest sensitivity pattern in this study was levofloxacin which is a quinolone. This is similar to other reports where quinolones were the most effective and sensitive antibiotics to the organisms causing UTI. ${ }^{19,23}$ All quinolones used in this study had good antibiotic sensitivity pattern: $92.5 \%$ for levofloxacin, $77.4 \%$ for ofloxacin, and $66.7 \%$ for ciprofloxacin. Quinolones are expensive and have been associated with teratogenicity in first trimester and risk of auditory and vestibular toxicity in the fetus in later trimesters, and are therefore contraindicated in pregnancy. However, for recurrence and persistent UTI, quinolones could be used with caution in late pregnancy or postpartum after counseling, especially if it is the only sensitive drug, as it is also secreted in breast milk.

In this study, cephalosporins had a remarkable antibiotic sensitivity pattern of $87.3 \%$ for cefpodoxime and $66.7 \%$ for ceftriaxone. Cephalosporins, although expensive, are safe in pregnancy. Currently, most cephalosporins have both oral and parenteral combinations and have been noted to be the first line drug for pyelonephritis and the most commonly used antimicrobials for symptomatic UTI in hospital settings. ${ }^{4,25}$

Gentamicin was the only other antibiotic in this study with an overall good sensitivity pattern of greater than $50 \%$, 


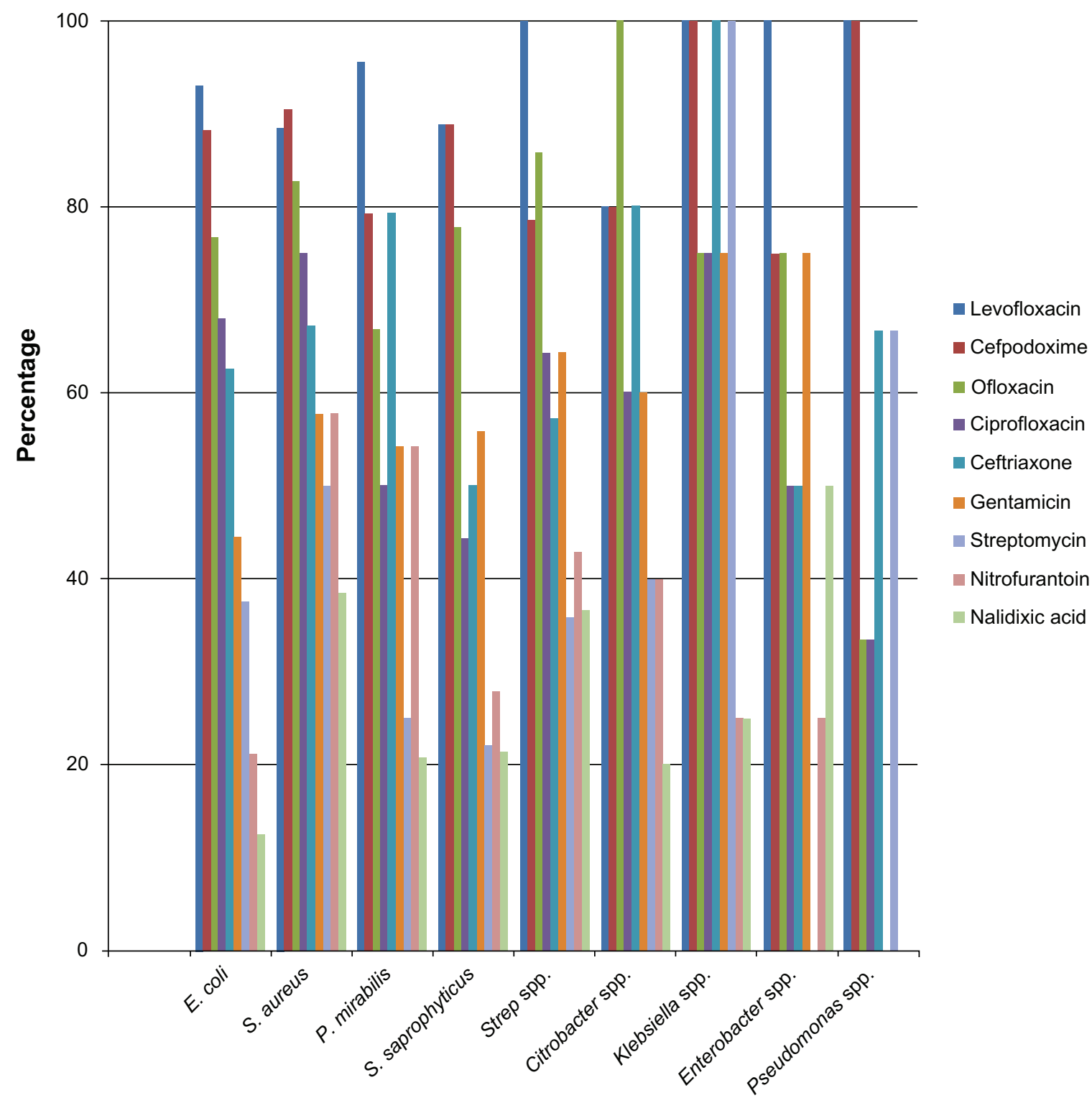

Figure 3 Bar graph showing antibiotic sensitivity pattern of uropathogens with drugs that showed individual sensitivity pattern of $\geq 50 \%$.

aside from the quinolones and the cephalosporins. However, it has only parenteral formulations and is associated with possible risk of auditory and vestibular nerve damage to the fetus. ${ }^{25}$ All the other antibiotics used in this study had a poor antibiotic sensitivity pattern. Surprisingly, these are the commonly available and cheap drugs. They include streptomycin, nitrofurantoin, nalidixic acid, chloramphenicol, tetracycline, ampicillin/cloxacillin, amoxicillin, and cotrimoxazole. The poor antibiotic sensitivity pattern of the above commonly available drugs could be due to the practice of self-medication, visiting pharmacy shops manned by non-professionals leading to under dosage and indiscriminate abuse of drugs in our environment. The above practice leads to emergence of resistant strains among the UTI causing bacteria. This increases the cost of treatment because the quinolones and cephalosporins, which have excellent sensitivity patterns, are expensive.

In this study, nitrofurantoin showed a good sensitivity pattern to $S$. aureus (60\%) and P. mirabilis (50.4\%), even though the overall sensitivity was poor (33.7\%). Other studies have demonstrated increased sensitivity of nitrofurantoin to bacterial isolates from urine of pregnant women with or without symptoms of UTI. ${ }^{4,9,18,22}$ Hence, recommendation of nitrofurantoin as a first line drug has also been made in such studies. ${ }^{4,9,18}$ As such, nitrofurantoin could be very useful in the management of UTI in pregnancy, especially when the sensitivity result shows that the isolated organism has good sensitivity to nitrofurantoin. 
In conclusion, $E$. coli was the most common bacteria isolated from urine of pregnant woman with UTI in our setting. Enterococcus, especially Staphylococci, constituted a significantly high proportion of bacterial isolates in this study. Quinolones and cephalosporins were the most sensitive drugs to all the micro organisms isolated from symptomatic cases in this study. Cephalosporins, like ceftriaxone or cefpodoxime, could be administered empirically because of their high sensitivity and wide spectrum of activity against micro organisms causing UTI in pregnancy seen in this study. Thereafter, the cheap and readily available antibiotics like nitrofurantoin could be used to replace the cephalosporins if the antibiotic sensitivity of the offending bacterial isolates shows susceptibility to these cheap readily available antibiotics. However, considering the morbidity and mortality that may complicate UTI in pregnancy if not adequately managed, the cephalosporins, even though expensive, are cost effective and safe when appropriately used in pregnancy. However, the cost implication could be addressed by effective implementation of National Health Insurance Scheme. Through the National Health Insurance Scheme, cephalosporins could be made available at no financial burden to these pregnant women with symptomatic UTI. However, in the interim, the government could subsidize the cost of this potent antibiotic to reduce perinatal and maternal morbidity and mortality.

\section{Limitations}

The study was a hospital based study and may not truly reflect findings in the rural areas and the entire state. The antibiotic sensitivity test against bacteria in the laboratory is an in vitro activity and may not exactly reflect the in vivo activity.

There may be some observational error, especially with the error due to parallax in measuring the inhibition zone diameter.

\section{Acknowledgment}

We sincerely appreciate the management of the Federal Teaching Hospital Abakaliki, Ebonyi State for their financial support in carrying out the laboratory investigations in this study.

\section{Disclosure}

The authors report no conflict of interest in this study.

\section{References}

1. Addo VN. Urinary Tract Infection in pregnancy. In: Kwawukume EY, Emuveyan EE, editors. Comprehensive Obstetrics in the Tropics. Dansoman: Asante and Hittscher Printing Press Limited; 2002: 261-267.
2. Cunningham FG, Gant NF, Leveno KJ, Gilstrap LC III, Hauth JC, Wenstrom KD. Renal and Urinary Tract Disorders. In: Andrea Seils, Noujaim SR, Daris K, editors. Williams Obstetrics. 21st ed. New York: McGraw-Hill Medical Publishing Divsion; 2001: 1251-1272.

3. Borchert D. Sheridan L, Papatsoris A, et al. Prevention and treatment of urinary tract infection with probiotics: review and research perspective. Indian J Urol. 2008;24(2):139-144.

4. Mathia E, Thomas RJ, Chandy S, Mathai M, Bergstrom S. Antimicrobials for the treatment of urinary tract infection in pregnancy: practice in southern India. Pharmacoepidermiol Drug Saf. 2004;13(9): 645-652.

5. Johnson EK, Wolf JS. Urinary Tract Infections in Pregnancy. Medscape. Available from: http://emedicine.medscape.com/article/452604overview. Accessed October 12, 2013.

6. Patterson TF, Andriole VT. Bacteriuria in pregnancy. Infect Dis Clin North Am. 1987;1(4):807-822.

7. Schieve LA, Handler A, Hershow R, Persky V, Daris F. Urinary tract infection during pregnancy: its association with maternal morbidity and perinatal outcome. Am J Public Health. 1994;84(3):405-410.

8. Nnatu S, Essien EE, AkinKugbe A, Odum CU. Asymptomatic bacteriuria in pregnant Nigerian patients. Clin Exp Obstet Gynecol. 1989;16:126-128.

9. Ezechi OC, Fasubaa OB, Dare FO. Antibiotic sensitivity patterns of microbial Isolates from urine of pregnant women with urinary tract infections. Trop J Obstet Gynaecol. 2003;20(2):113-115.

10. Abdul IF, Onile BA. Bacterial isolates from urine of women in Ilorin and their antibiotic susceptibility patterns. Trop J Obstet Gynaecol. 2001;18(2):61-65.

11. Arias F. Abnormalities of the urinary system during pregnancy. In: Daftary SN, Bhide AG, editors. Practical Guide to High Risk Pregnancy and Delivery. A South Asian Perspective. 3rd ed. New Delhi: Elsevier; 2008:489-505.

12. Alausa KO, Montefiore D, Sobayo E. Problems in the diagnosis of urinary tract infections. Niger Med J. 1979;9:107-111.

13. Onyemenem TN, Ekweozor CC. Urinary tract infection in Ibadan: Causative organisms and antimicrobial sensitivity patterns. Afr J Med Sci. 1996;25:165-169.

14. Ebonyi state [website on the Internet]. Online Nigeria [updated March 1, 2003]. Available from: http://www.Onlinenigeria.com/links/ebonyiadv. asp. Accessed November 2, 2011.

15. Cheesbrough M. Microbiological tests. In: District Laboratory Practice in Tropical Countries Part 2. Cambridge, UK: Cambridge University Press; 2004:1-266.

16. Olusanya O, Okpere EE, Ezimokhai M. The importance of social class in voluntary fertility control in a developing country. West Afr J Med. 1985;4:252-255.

17. Jido TA, Nwankwo EOK, Magaji N. Preliminary microbiologic observation in pregnant women with suspected urinary tract infection in Kano, Nigeria. Nigeria Journal of Basic and Clinical Sciences. 2006;4(1-2):1-4.

18. Onuh SO, Umeora OUJ, Igbarese HO, Aziken ME, Okpere EE. Microbiological isolates and antibiotics sensitivity pattern of urinary tract infection in pregnancy in Benin-city, Nigeria. Ebonyi Medical Journal. 2006;5(2):48-52.

19. Kolawole AS, Kolawole OM, Kandaki-Olukemi YT, Babatunde SK, Durowade KA, Kolawole CF. Prevalence of urinary tract infection (UTI) among patients attending Dalhatu Araf Specialist Hospital, Lafia, Nasarawa State, Nigeria. Int J Med Med Sci. 2009;1(5):163-167.

20. Aka PA, Onah HE. Urinary tract infection in pregnancy in a rural Nigerian setting. W Afr J Pharmacol Drug Res. 1997;13(1-2):8-12.

21. Delzell JE, Leferre ML. Urinary tract infections in pregnancy. Am Fam Physician. 2000;61:713-721.

22. Assefa A, Asrat D, Woldeamanent YG, Hiwot Y, Abdella A, Melesse T. Bacterial profile and drug susceptibility pattern of urinary tract infection at Tikur Anbessa Specialized Hospital Addis Ababa, Ethiopia. Ethiop Med J. 2008;46(3):227-235. 
23. Aziz MK, Habib-Ullah K, Ihsan-Ullah M, Bushara A, Syed HS. Antimicrobial sensitivity pattern of urine isolates from asymptomatic bacteriuria during pregnancy. Biomedica. 2006;22:67-70.

24. Ezeome IV, Ikeme AC, Okezie OA, Onyebueke EA. Asymptomatic bacteriuria (ASB) in pregnant women in Enugu, Nigeria. Trop J Obstel Gynaecol. 2006;23(1):12-13.
25. Duft P. Antibiotic selection in Obstetric: making cost effective choices. Clin Obstet Gynaecol. 2002;45:59-72.

\section{Publish your work in this journal}

Infection and Drug Resistance is an international, peer-reviewed openaccess journal that focuses on the optimal treatment of infection (bacterial, fungal and viral) and the development and institution of preventive strategies to minimize the development and spread of resistance. The journal is specifically concerned with the epidemiology of antibiotic
Dovepress

resistance and the mechanisms of resistance development and diffusion in both hospitals and the community. The manuscript management system is completely online and includes a very quick and fair peerreview system, which is all easy to use. Visit http://www.dovepress.com/ testimonials.php to read real quotes from published authors.

Submit your manuscript here: http://www.dovepress.com/infection-and-drug-resistance-journal 